\title{
Myocardial infarction in a young man with systemic lupus erythematosus, deep vein thrombosis, and antibodies to phospholipid
}

\author{
R A ASHERSON, I R MACKAY, * E N HARRIS \\ From the Lupus-Arthritis Research Unit, the Rayne Institute, St Thomas' Hospital, London, and *the Clinical \\ Research Unit, Walter and Eliza Hall Institute of Medical Research, Royal Melbourne Hospital, Victoria, \\ Australia
}

SUMMARY From the age of 17 a young man had recurrent venous thrombosis, with pulmonary embolism on two occasions. Laboratory investigations showed increased DNA binding, thrombocytopenia, positive antinuclear antibodies, and immunoglobulin A deficiency. A plasminogen activator deficiency was suspected because the euglobulin lysis time was considerably prolonged. Variant lupus was diagnosed. He had a severe myocardial infarct at the age of 20 and subsequent investigations showed the presence in serum of the lupus anticoagulant and antibodies to cardiolipin. The presence of these antiphospholipid antibodies explains the features of his illness and establishes that this case fits into a subset of systemic lupus erythematosus characterised by thrombotic events.

Venous occlusion, particularly deep leg vein thrombosis and thromboses of the renal vein and inferior vena cava, ${ }^{1}$ are all reported to be more common in a type of systemic lupus erythematosus in which there are circulating antibodies to phospholipid (the lupus anticoagulant) ${ }^{2}$ and cardiolipin. ${ }^{3}$ Arterial occlusions, resulting from an arteritis/vasculitis or thrombotic disease of large vessels such as the aorta and its major branches, ${ }^{4}$ the subclavian and brachial arteries, ${ }^{5}$ and other larger vessels occur infrequently in systemic lupus erythematosus. An association between occlusions of the large arteries and antiphospholipid antibodies occasionally leads to gangrene and bowel infarctions. ${ }^{67}$

We describe a patient with a plasminogen activator deficiency who had a myocardial infarction at the age of 20 years. Later antibodies to phospholipid were found in his serum.

\section{Case report}

In March 1978 a boy aged 17 complained of right

Requests for reprints to Dr R A Asherson, The Lupus-Arthritis Research Unit, The Rayne Institute, St Thomas' Hospital, London SE1 7EH. sided pleuritic chest pain which was diagnosed as Bornholm disease. In June 1978 he complained of pain in the left calf which resolved after 10 days; a deep venous thrombosis was diagnosed. In September 1978 venous thrombosis occurred in the left leg; a radioisotopic scan showed evidence of pulmonary embolism and a venogram showed a left ileofemoral blockage. In February 1979 subcostal and shoulder pain developed and right upper lobe pneumonia was diagnosed. Investigations at the Royal Melbourne Hospital showed that he had a positive test for antinuclear antibody (titre 1:1000 with a speckled pattern) and a positive test for antibody to DNA (there was binding of $43 \%$ in a Farrtype assay; normal $<20 \%$ ). The serum concentration of immunoglobulin $G$ was increased to $16.9 \mathrm{~g} / 1$ (normal $<16 \mathrm{~g} / \mathrm{l}$ ) and immunoglobulin $\mathrm{A}$ was considerably reduced $(<0 \cdot 15 \mathrm{~g} / \mathrm{l})$. Concentrations of the serum complement components C3 and $\mathrm{C} 4$ were within normal limits, and the Venereal Disease Research Laboratories test was negative. The lupus erythematosus cell test was negative.

A plasminogen activator deficiency was diagnosed because the euglobulin lysis time was prolonged. A blood pressure cuff $(80 \mathrm{~mm} \mathrm{Hg})$ was applied for 10 minutes to induce release of tissue plasminogen acti- 


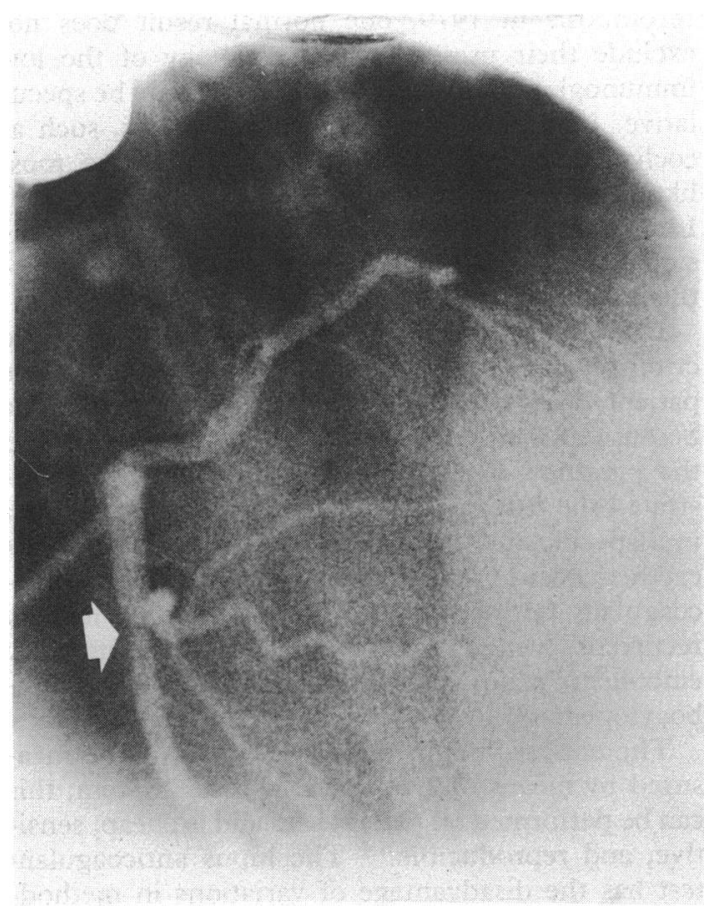

Figure Coronary arteriogram showing slight narrowing of the left anterior descending coronary artery just beyond the first diagonal branch. The distal third of the left anterior descending coronary artery is diffusely narrowed and there is poor filling of its terminal branches.

vator from the vein wall. The results were: prestress, 6 hours (normal 2-4 hours) and post-stress, 5 hours 23 minutes (normal 40-80 minutes). He was treated with ethyloestrenol.

In May $1979^{\circ}$ he suffered another pulmonary embolus and venography again showed a clot in the left femoral vein. Swelling of the left thigh and calf persisted. The spleen was palpable. His illness was diagnosed as variant lupus. He was treated with warfarin and the ethyloestrenol was continued. The antinuclear antibody test remained positive (titre $1: 100-1: 500$, speckled pattern) as did the test for DNA antibody.

Further tests for euglobulin lysis time were performed from 1979 to 1980 inclusive. The results pre-stress ranged from $5 \mathrm{~h} 40 \mathrm{~min}$ to $6 \mathrm{~h} 16 \mathrm{~min}$ and post-stress from $4 \mathrm{~h} 40 \mathrm{~min}$ to $5 \mathrm{~h} 44 \mathrm{~min}$. Ethyloestrenol was stopped as it was deemed to be ineffective. In July 1981 he complained of persistent chest pains after a weekend visit to a ski resort. Myocardial infarction was diagnosed on the basis of electrocardiographic findings, raised serum activities of cardiac enzymes (creatine kinase was successively $508,392$, and $97 \mathrm{IU} / 1)$, a raised leucocyte count (12.1 $\left.\times 10^{9} / 1\right)$, and evidence of left ventricular infarction from a technetium-99m (pyrophosphate) scan. A chest $x$ ray showed a moderately enlarged heart. A coronary arteriogram (fig) showed normal right, left main, and circumflex arteries, and slight narrowing of the left anterior descending artery and a hypokinetic left ventricular wall. Laboratory tests at this time showed a raised erythrocyte sedimentation rate (73-93 mm/hour), kaolin partial thromboplastin time within normal limits, a normal platelet count, and a negative Coombs' test. The euglobulin lysis time was not measured during this admission.

In February 1983 the patient was seen at Hammersmith Hospital. He was symptom free and physical examination was normal. The left thigh and calf were swollen and there was bluish discolouration of the left foot. The platelet count was decreased $(88 \times$ $10^{9} / 1$ ) and the prothrombin time was $23 \mathrm{~s}$ (normal $14 \mathrm{~s}$ ). The kaolin partial thromboplastin time was $95 \mathrm{~s}$ (control $40 \mathrm{~s}$ ) and the clotting abnormality was not corrected by the addition of normal plasma, indicating the presence of an inhibitor of coagulation. The Oxford disseminated lupus erythematosus inhibitor test confirmed that the inhibitor present was of the lupus type. A strongly positive anticardiolipin antibody test provided further support for this finding.

The antinuclear antibody test was weakly positive (titre 1:40, speckled pattern), but the test for DNA antibody was negative $(12 \%)$ and antibodies to extractable nuclear antigens were not demonstrable. Immune complexes were shown to be present in serum by the monoclonal rheumatoid factor binding assay.

The concentration of serum immunoglobulin $\mathbf{G}$ was again raised $(17.7 \mathrm{~g} / \mathrm{l})$ and, as previously, the concentration of immunoglobulin A was considerably reduced $(<0.45 \mathrm{~g} / \mathrm{l})$. The euglobulin lysis time was within normal limits.

In October 1984 the patient was well, apart from a swollen left thigh and calf and venous stasis in the left foot. He is now receiving continuous anticoagulation with warfarin and has had no further problems.

\section{Discussion}

This patient initially presented with an illness characterised by recurrent venous thromboses and pulmonary emboli. Originally, on the basis of a greatly prolonged euglobulin lysis time, plasminogen activator deficiency was diagnosed. The fluorescent antinuclear antibody test was positive, but because all the criteria for a diagnosis of systemic lupus erythematosus were not met variant lupus was diagnosed. He was treated with ethyloestrenol which at 
the time was believed to ameliorate states of decreased fibrinolytic activity, ${ }^{8}$ but this seemed ineffective, and later he received warfarin. Despite anticoagulant treatment he had a myocardial infarct 3 years later when he was 20 . Serum tests for the lupus anticoagulant (antiphospholipid antibodies) and antibody to cardiolipin were later found to be positive. His disease belongs to a subgroup of systemic lupus erythematosus in which thrombotic events are associated with the presence of antiphospholipid antibodies. These are immunoglobulins of the $G$ or $M$ class, and they inhibit the activity of the prothrombin activator complex (factor $\mathrm{V}$, factor $\mathrm{Xa}$, calcium, and phospholipid). They appear to react specifically with phospholipids including those of platelets. The presence of these antibodies is paradoxically associated with venous, and occasionally arterial, thrombosis and several theories have been formulated to account for this effect.

Carreras etal demonstrated that an immunoglobulin $G$ fraction from a patient with high lupus anticoagulant activity reduced prostacyclin production in rat aortic ring and human myometrium. ${ }^{9}$ Sanfellipo and Drayna reported decreased kaolin induced fibrinolytic activity in their patients with the lupus anticoagulant, ${ }^{10}$ and decreased fibrinolytic activity was also found in four similar patients described by Elias and Eldor. ${ }^{11}$ Prekallikrein (Fletcher factor) may be inhibited by the lupus anticoagulant and the possible consequent impairment of fibrin clearance may result in clotting. The prolonged euglobulin lysis time in our patient was evidence of impaired fibrinolytic activity in the plasma.

Kaolin induced fibrinolytic activity does not necessarily correspond to the activity measured by the conventional euglobulin lysis time, which was performed initially in a clinical setting to define a coagulation defect in our patient. More detailed assays to elucidate further the cause of prolonged euglobulin lysis time were not performed because they were not routinely available at that time.

Coronary occlusion with myocardial infarction is infrequent early in the course of systemic lupus erythematosus, but may supervene late in the disease, usually as a result of severe atherosclerosis or coronary arteritis. ${ }^{12}$ Landi et al first mentioned the occurrence of myocardial infarction in a patient with the lupus anticoagulant. ${ }^{13}$ In addition, the presence of anticardiolipin antibodies and lupus anticoagulant has been linked with recurrent fetal loss, cerebral infarction, pulmonary hypertension, and chorea ${ }^{14}$ These antibodies are likely to have been involved in the genesis of the coronary occlusion in the present patient. Although the kaolin partial thromboplastin time was normal at the time of his admission for the investigation of the deep vein thrombosis in 1979, one normal result does not exclude their presence. The aetiology of the low immunoglobulin A concentration can only be speculative. In the absence of the usual causes, such as coeliac disease or nephrotic syndrome, the most likely explanation is the autoimmune disease itself. Low immunoglobulin A concentrations are occasionally associated with systemic lupus erythematosus.

In conclusion, in the absence of other diagnostic criteria for systemic lupus erythematosus this patient was described as having variant lupus because of a raised DNA antibody assay result and the presence of antinuclear antibody. He demonstrated the features recently described as occurring in a specific subset of patients with systemic lupus erythematosus in the presence of the lupus anticoagulant and antibodies to cardiolipin, namely recurrent venous thromboses and pulmonary embolism, major arterial thrombosis, and thrombocytopenia.

The anticardiolipin antibodies can now be measured by means of a solid phase assay system; this can be performed on patient sera and is cheap, sensitive, and reproducible. ${ }^{14}$ The lupus anticoagulant test has the disadvantage of variations in methodology from laboratory to laboratory and the need for freshly prepared plasma for reliable results. A recent study from Sweden has shown a high frequency of anticardiolipin antibodies in young survivors of myocardial infarction and a strong correlation with post-infarct thrombotic events, including reinfarction. ${ }^{15}$

We suggest that anticardiolipin antibodies should be sought in all younger patients with unexplained thrombotic disease including arterial thrombosis.

We thank Dr G R V Hughes and Dr A E Gharavi for their assistance in this case.

\section{References}

1 Asherson RA, Lanham JG, Hull GR, Gharavi AE, Hughes GRV. Renal vein thrombosis in systemic lupus erythematosus: association with the "lupus anticoagulant". Clin Exp Rheumatol 1984;2:75-9.

2 Boey ML, Colaco CB, Gharavi AE, Elkon KE, Loizou S, Hughes GRV. Thrombosis in SLE: striking assoication with the presence of the "lupus anticoagulant". Br Med F 1983;287:1021-3.

3 Harris EN, Gharavi AE, Boey ML, et al. Anticardiolipin antibodies: detection by radioimmunoassay and association with thrombosis in SLE. Lancet 1983; ii:1211-4.

4 Bernhard GC, Lange RL, Hensley GT. Aortic disease with vascular insufficiency as the principal manifestation of systemic lupus erythematosus. Ann 
Intern Med 1969;71:81-7.

5 Ferrante MF, Myerson GD, Goldman JA. Subclavian artery thrombosis mimicking the aortic arch syndrome in systemic lupus erythematosus. Arthritis Rheum 1982;25:1501-4.

6 Asherson RA, Harris EN, Gharavi AE, et al. Arterial occlusions associated with antibodies to cardiolipin. Arthritis Rheum 1985;28:589.

7 Asherson RA, Morgan SH, Harris EN, Gharavi AE, Krausz T, Hughes GRV. Arterial occlusion causing large bowel infarction-a reflection diathesis in SLE. Clin Rheumatol 1986;(5)102-6.

8 Isaacson S, Nilsson IM. Effect of treatment with combined phenformin and ethyloestrenol on the coagulation and fibrinolytic system. Scand $\boldsymbol{f}$ Haematol 1970;7:404-8.

9 Carreras LO, Defreyn G, Machin SJ, et al. Arterial thrombosis, intrauterine death and "lupus anticoagulant". Detection of immunoglobulin interfering with prostacyclin formation. Lancet 1981; i:244-6.
10 Sanfellipo MJ, Drayna CJ. Prekallikrein inhibition associated with the "lupus anticoagulant": a mechanism of thrombosis. Am $\mathcal{F}$ Clin Pathol 1982;77: 275-9.

11 Elias M, Eldor A. Thromboembolism in patients with the lupus-type circulating anticoagulant. Arch Intern Med 1984;14:510-5.

12 Tsakraklides VG, Blieden LE, Edwards JE. Coronary atherosclerosis and myocardial infarction associated with SLE. Am f Med 1974;87:637-41.

13 Landi G, Calloni MV, Sabbadini MG, Mannucci PM, Candelise L. Recurrent ischaemic attacks in two young adults with "lupus anticoagulant". Stroke 1983;3:377-9.

14 Feinstein D. Lupus anticoagulant, thrombosis, and fetal loss. $N$ Engl f Med 1986;313:1348-50.

15 Hamsten A, Norberg R, Bjorkholm M, de Faire U, Holm G. Antibodies to cardiolipin in young survivors of myocardial infarction: an association with recurrent cardiovascular events. Lancet 1986;i:113-6.

\section{Notices}

\section{British Cardiac Society}

The Autumn Meeting will be held at the Wembley Conference Centre, London, on 25 to 27 November 1986, and the closing date for receipt of abstracts was 11 July 1986.

The Annual General Meeting for 1987 will take place in Dundee on 8 and 9 April 1987, and the closing date for receipt of abstracts will be 6 January 1987.

\section{Thrombosis and haemostasis}

The XIth Congress of the International Society on Thrombosis and Haemostasis will be held in Brussels on 6 to 10 July 1987. Inquiries to: H R Lijnen, $\mathrm{PhD}$, Centre for Thrombosis and Vascular Research, Campus Gasthuisberg, Herestraat 49, B-3000 Leuven, Belgium.

\section{Pierre Rijlant prize}

Applications are invited for the Pierre Rijlant prize for cardiac electrophysiology. For further details write to Professor A Verniory, Secretary, Pierre Rijlant Foundation, Rue Ducale 1, B-1000 Brussels, Belgium. 